\title{
BMJ Open Socioeconomic inequalities in youth smoking in Brazil
}

\author{
Sandhi Maria Barreto, ${ }^{1}$ Roberta Carvalho de Figueiredo, ${ }^{1}$ Luana Giatti ${ }^{1,2}$
}

To cite: Barreto SM, de Figueiredo RC, Giatti L. Socioeconomic inequalities in youth smoking in Brazil. BMJ Open 2013;3:e003538. doi:10.1136/bmjopen-2013003538

- Prepublication history for this paper is available online. To view these files please visit the journal online (http://dx.doi.org/10.1136/ bmjopen-2013-003538)

Received 3 July 2013 Revised 15 October 2013 Accepted 16 October 2013

CrossMark

\begin{abstract}
${ }^{1}$ Faculty of Medicine, Postgraduate Program in Public Health, Universidade Federal de Minas Gerais, Belo Horizonte, Brazil

${ }^{2}$ Department of Clinical and Social Nutrition, Universidade Federal de Ouro Preto, Ouro Preto, Brazil
\end{abstract}

Correspondence to Professor Sandhi M Barreto; sandhi.barreto@gmail.com

\section{ABSTRACT}

Objective: The contribution of smoking to socioeconomic inequalities in health is increasing worldwide, including in Brazil. Youth smoking may play an important role in the increasing social inequalities related to smoking. This study investigates social determinants of smoking among 15-year-old to 19-year-old individuals.

Design: Cross-sectional study.

Setting: The study uses data of 3536 participants aged 15-19 years of age of the Global Adult Tobacco Survey (GATS) and the National Household Sample Survey (Pesquisa Nacional por Amostragem de Domicilio, PNAD) obtained from household interviews. Smoking was defined as currently smoking tobacco products, regardless of frequency. Household socioeconomic indicators included per capita income, the educational level and sex of the head of the household, the presence of smoking restrictions and the number of smokers (excluding adolescents). Adolescent social factors included years of delaying school and social status (full-time student, working, and neither working nor studying). The hierarchical logistic regression analysis considered the effect of the complex sampling design.

Results: From 3536 participants, $6.2 \%$ were smokers (95\% $\mathrm{Cl} 5.4$ to 7.1$)$. More men than women had the habit of smoking (7.2\%; 5.9 to 8.6 vs $3.6 \%$; 2.7 to 4.6$)$. The likelihood of smoking was significantly greater for men and older teens. There was an upward trend in the OR of smoking according to the number of smokers in the house. Adolescents living in households with no smoking restrictions had a greater likelihood of being smokers. OR of smoking rose as the number of years of delaying school increased, being about three times greater among adolescents who were working and five times greater among those who were neither studying nor working. Conclusions: Results demonstrate that socioeconomic inequality in smoking is established at younger ages and that school delay as well as school abandonment may contribute to increased smoking-related inequalities. Smoking restrictions at home were protective against adolescents becoming smokers. Living with other smokers was a strong predictor of adolescents becoming smokers.

\section{INTRODUCTION}

Cigarette smoking has fallen sharply in Brazil; in approximately two decades, the smoking prevalence among individuals aged 18 years

\section{Strengths and limitations of this study}

- The main strength of this study is its analysis of the social determinants, at the household and individual levels, of teenage smoking using a nationwide household sample in a large middle-income country.

- The main limitation is the lack of information about the relationship between adolescents and other smokers in the household.

- Results reinforce that household smoking restrictions protect against adolescent smoking.

and older decreased $48 \%$, from $34.8 \%$ in 1989 to $18.2 \%$ in $2008,{ }^{1}$ preventing almost 420000 (260 000-715000) deaths. ${ }^{2}$ Such achievements have been attributed largely to Brazil's strong upstream anti-tobacco policies, combined with an increased access to tobacco cessation treatments. $^{23}$

However, the contribution of smoking to socioeconomic inequalities in health is increasing in Brazil. According to data from the World Health Survey, 2002-2004, smoking rates were higher among poor men and women ( $74 \%$ and $59 \%$, respectively), even after controlling for age, marital status, education, employment and urban/rural residence. ${ }^{4}$ The results of the Global Adult Tobacco Survey (GATS) Brazil showed that there were almost twice as many tobacco users with no or less than a year of schooling, compared with tobacco users with 11 or more years of education. ${ }^{5}$

Early initiation of tobacco use could be a key component in the increasing social inequalities of smoking and its related morbidity and mortality. ${ }^{6}$ Analyses of three birth cohorts in Italy showed that the increase in smoking inequalities among men and women was mainly due to growing inequalities in smoking initiation rates. Studies have shown that most regular adult smokers become addicted in their teens. ${ }^{7-9}$ In addition, early smoking has been associated with higher levels of tobacco dependence, increased difficulty in smoking cessation and more negative health outcomes in adulthood. ${ }^{10-13}$ 
In 2004, approximately $70 \%$ of adult smokers residing in large Brazilian cities had begun to smoke before the age of 20 years. ${ }^{14}$ However, youth smoking seems to be more frequent among socially disadvantaged groups. ${ }^{15} 16$ In Brazil, among daily or former daily smokers, the proportion of individuals who started smoking before 15 years of age was twofold greater among those with no or less than 1 year of schooling than among those with 8 years of schooling or more. ${ }^{5}$

A few studies have specifically addressed the social determinants of teenage smoking in Brazil, ${ }^{17-19}$ and none has been undertaken in a nationwide household sample. This study investigated the social determinants of current smoking among participants of 15-19 years of age in the GATS Brazil. In particular, we investigated whether school delay and abandonment, as well as early entry to work, which are regarded as early markers of future socioeconomic disadvantage, were independently associated with smoking among teenagers.

\section{METHODS}

Participants

This study used data from GATS, which was carried out in a random subsample of the National Household Sample Survey (Pesquisa Nacional por Amostragem de Domicilio, PNAD). PNAD was conducted in 2008 by the Brazilian Institute of Geography and Statistics (Instituto Brasileiro de Geografia e Estatstica, IBGE) and the Ministry of Health. PNAD and GATS Brazil used a fourstage complex probabilistic household sample (municipality, census tract, household and individual) and was representative of the national and regional levels. Further details on the sampling design can be found at http://www.who.int/tobacco/surveillance/en_tfi_gats_ 2010_brazil.pdf.

The PNAD questionnaires provided socioeconomic information about households and selected individual characteristics and health-related factors, and the GATS questionnaire provided a detailed information on tobacco use and exposure. GATS Brazil aimed to include 40000 individuals aged 15 years and older with a response rate of $95.2 \%$. Of 39425 interviews, 33680 were conducted in urban areas and 5745 in rural areas. Bearing in mind our objectives, we studied all adolescents aged 15-19 years who participated in GATS Brazil, totalling 3536 individuals.

\section{Variables}

The response variable of the study was current smoking, defined as being a current smoker regardless of frequency, and it was grouped into two categories (yes, no). The proportion of daily smokers, age at initiation and the number of cigarettes smoked per day among daily smokers were used to describe the smoking behaviour.

The explanatory variables were grouped into three sets of covariables in this analysis. Household socioeconomic factors included location (urban, rural), household per capita income grouped in quintiles, highest education level attained by the head of the household in number of years completed $(0-8,9-11$, $12-14,15$ and more) and female head of household (no, yes).

The second set of covariables consisted of household smoking characteristics, which included the number of smokers in the household, excluding the participating adolescent $(0,1,2,3$ or more) and smoking restrictions at home (not allowed, generally not allowed and allowed). The category 'allowed' also included an absence of smoking restrictions.

The last set of covariables included the adolescents' characteristics: sex; age $(15,16,17,18$, and 19 years); self-declared race/skin colour (white, black, brown, Asian descent and indigenous); social status (full-time student, only working, working and studying and neither studying nor working); school delay, defined as the difference in years of schooling between the individual's current school grade and the school grade in which he/ she was expected to be given his/her age (none, 1, 2, 3 years or more). A negative difference in school delay was treated as no difference. The Asian descent and indigenous were combined as 'other' because the number of individuals was very small.

\section{Statistical analysis}

First, we described the prevalence of smoking, the proportion (with $95 \%$ CIs) of daily smokers, age at initiation and the mean and median numbers of cigarettes smoked per day by sex. Next, we performed a descriptive analysis of the distribution of adolescents according to individual and household socioeconomic indicators (table 1).

Associations between each explanatory variable and current smoking were measured by Pearson's $\chi^{2}$ test with a $\mathrm{p}$ value $<0.05$. Variables with $\mathrm{p}<0.20$ were included in the multivariable analysis. The magnitude of the associations was measured using ORs, and 95\% CIs were obtained by multiple logistic regression. The 'svy' procedure, available in Stata V.11.0, was used to account for the effect of the GATS complex survey design. Multicollinearity among household covariables was assessed using a variance inflation factor and the condition number. Multicollinearity was not found among the variables (tables 2 and 3).

To account for the hierarchical levels of the determination of youth smoking, multivariable analysis was performed, assuming that the socioeconomic household factors were the most distal factors, household smoking indicators were intermediate factors, and individual socioeconomic factors were the most proximal factors. ${ }^{20}$ Thus, after considering the sex and age of the adolescents, we began hierarchical modelling by simultaneously introducing the distal variables (educational level and sex of the head of the household and household per capita income), keeping the factors related to 
Table 1 Distribution of participants according to socioeconomic and household characteristics (Brazil 2008)

\begin{tabular}{|c|c|c|}
\hline Characteristics & $\begin{array}{l}\text { Per } \\
\text { cent }\end{array}$ & $95 \% \mathrm{Cl}$ \\
\hline \multicolumn{3}{|l|}{$\overline{\operatorname{Sex}}$} \\
\hline Male & 50.4 & 48.6 to 52.3 \\
\hline Female & 49.6 & 47.7 to 51.4 \\
\hline \multicolumn{3}{|l|}{ Age (years) } \\
\hline $15-16$ & 40.9 & 39.1 to 42.7 \\
\hline $17-19$ & 59.1 & 57.0 to 60.8 \\
\hline \multicolumn{3}{|l|}{ Self-declared race/skin colour } \\
\hline White & 44.7 & 43.1 to 46.4 \\
\hline Black & 6.5 & 5.6 to 7.4 \\
\hline Brown & 48.1 & 46.4 to 49.8 \\
\hline Other* & 0.7 & 0.3 to 0.8 \\
\hline \multicolumn{3}{|l|}{ School delay (years) } \\
\hline None & 54.0 & 52.3 to 55.7 \\
\hline One & 12.5 & 11.3 to 13.7 \\
\hline Two & 10.5 & 9.3 to 11.5 \\
\hline Three or more & 23.0 & 21.5 to 24.4 \\
\hline \multicolumn{3}{|l|}{ Social status } \\
\hline Full student & 46.3 & 44.4 to 48.1 \\
\hline $\begin{array}{l}\text { Only working or working and } \\
\text { studying }\end{array}$ & 40.2 & 38.4 to 42.0 \\
\hline Neither studying/neither working & 13.5 & 12.2 to 14.7 \\
\hline \multicolumn{3}{|l|}{ Household per capita income } \\
\hline $5^{\circ}$ quintile (highest) & 20.8 & 19.3 to 22.3 \\
\hline $4^{\circ}$ quintile & 20.7 & 19.2 to 22.2 \\
\hline $3^{\circ}$ quintile & 19.9 & 18.3 to 21.3 \\
\hline $2^{\circ}$ quintile & 18.9 & 17.5 to 20.3 \\
\hline $1^{\circ}$ quintile (lowest) & 19.7 & 18.2 to 20.9 \\
\hline \multicolumn{3}{|c|}{ Head of the household schooling (years) } \\
\hline $0-8$ & 55.9 & 54.2 to 57.7 \\
\hline $9-11$ & 16.8 & 15.4 to 18.1 \\
\hline $12-14$ & 21.6 & 20.1 to 23.1 \\
\hline $15+$ & 5.7 & 4.7 to 6.4 \\
\hline \multicolumn{3}{|l|}{ Female-headed household } \\
\hline No & 62.2 & 64.4 to 63.9 \\
\hline Yes & 37.8 & 36.0 to 39.5 \\
\hline \multicolumn{3}{|l|}{ Urban/rural dwelling } \\
\hline Urban & 82.9 & 81.6 to 84.2 \\
\hline Rural & 17.1 & 15.7 to 18.3 \\
\hline \multicolumn{3}{|l|}{ Number of smokers } \\
\hline Zero & 65.5 & 63.7 to 67.2 \\
\hline One & 25.3 & 23.6 to 26.8 \\
\hline Two & 8.1 & 7.1 to 9.1 \\
\hline Three or more & 1.1 & 0.7 to 1.5 \\
\hline \multicolumn{3}{|l|}{ Household smoking rule } \\
\hline Not allowed & 46.4 & 44.5 to 48.1 \\
\hline Generally not allowed & 13.3 & 12.0 to 14.5 \\
\hline Allowed & 40.3 & 38.5 to 42.1 \\
\hline \multicolumn{3}{|c|}{$\begin{array}{l}\text { Source: Brazilian National Household Sample Survey (PNAD, } \\
\text { 2008) and GATS, } 2008 \text {. } \\
\text { ^Included Asian descendent and Indigenous. } \\
\text { GATS, Global Adult Tobacco Survey; PNAD, Pesquisa Nacional } \\
\text { por Amostragem de Domicilio. }\end{array}$} \\
\hline
\end{tabular}

smoking that remained statistically significant $(p<0.05$; model 1). Then, we entered household smoking factors (number of smokers and smoking restrictions) and kept the statistically significant factors (model 2). Finally, we
Table 2 OR of regular smoking* according to adolescents' sociodemographic features and household socioeconomic and smoking characteristics; Brazil-2008

\begin{tabular}{|c|c|c|}
\hline Characteristics & OR (95\% Cl) & $\begin{array}{l}p \\
\text { Value }\end{array}$ \\
\hline \multicolumn{3}{|c|}{ Adolescents' characteristics } \\
\hline \multicolumn{3}{|l|}{ Sex } \\
\hline Male & 1.00 & $<0.01$ \\
\hline Female & $0.47(0.33$ to 0.64$)$ & \\
\hline \multicolumn{3}{|l|}{ Age (years) } \\
\hline $15-16$ & 1.00 & $<0.01$ \\
\hline $17-19$ & 3.77 (2.63 to 5.39$)$ & \\
\hline \multicolumn{3}{|c|}{ Self-declared race/skin colour } \\
\hline White & 1.00 & \\
\hline Black & $1.70(1.05$ to 2.75$)$ & 0.030 \\
\hline Brown & $1.02(0.77$ to 1.36$)$ & 0.854 \\
\hline Othert & $0.65(0.08$ to 4.84$)$ & 0.672 \\
\hline
\end{tabular}

Social status

Full student $\quad 1.00$

Only working or working $\quad 4.73(3.22$ to 6.92$)<0.001$ and studying

Neither studying/Neither $\quad 6.99(4.56$ to 10.70$)<0.001$ working

School delay (years)

None $\quad 1.00$

One $\quad 2.33(1.41$ to 3.84$)<0.001$

Two $\quad 3.40(2.11$ to 5.48$)<0.001$

Three or more $\quad 6.56(4.62$ to 9.33$)<0.001$

Household characteristics

Urban/rural dwelling

\begin{tabular}{|c|c|}
\hline Jrban & 1.00 \\
\hline & $0.80(0.54$ to 1.19$)$ \\
\hline
\end{tabular}

Household per capita income

$5^{\circ}$ quintile (highest) $\quad 1.00$

$4^{\circ}$ quintile $\quad 1.63(1.05$ to 2.51$) \quad 0.028$

$3^{\circ}$ quintile $\quad 1.03(0.64$ to 1.67$) \quad 0.314$

$2^{\circ}$ quintile $\quad 1.23(0.78$ to 1.96$) \quad 0.361$

$1^{\circ}$ quintile (lowest) $\quad 1.46$ (0.93 to 2.28) 0.093

Head of the household schooling (years)
$0-8$
1.00

9-11

$12-14$

0.57 (0.37 to 0.88$) \quad 0.011$

$15+$

$0.59(0.40$ to 0.85$) \quad 0.005$

$0.58(0.29$ to 1.16$) \quad 0.128$

Female-headed household

No

1.00

Yes

$1.02(0.77$ to 1.35$) \quad 0.855$

Number of smokers

$\begin{array}{ll}\text { Zero } & 1.00 \\ \text { One } & 1.93(1.42 \text { to } 2.63)<0.001 \\ \text { Two } & 3.00(1.98 \text { to } 4.53)<0.001 \\ \text { Three or more } & 9.01(4.45 \text { to } 18.19)<0.001\end{array}$

Household smoking rule

Not allowed

1.00

Generally not allowed $\quad 1.47$ (0.93 to 2.30$) \quad 0.092$

Allowed

2.18 (1.61 to 2.94$)<0.001$

Source: Brazilian National Household Sample Survey (PNAD, 2008) and GATS 2008.

${ }^{*}$ Report of having smoked 100 cigarettes in lifetime and currently smoking every day or not every day.

tIncluded Asian descendent and Indigenous.

GATS, Global Adult Tobacco Survey; PNAD, Pesquisa Nacional por Amostragem de Domicilio. 
Table 3 Results of the hierarchical regression analyses in adolescents examined the association between individual and household characteristics and smoking* (Brazil, 2008)

\begin{tabular}{|c|c|c|c|}
\hline Variables & Model 1 & Model 2 & Model 3 \\
\hline \multicolumn{4}{|l|}{ Household socioeconomic factors } \\
\hline $0-8$ & 1.00 & 1.00 & 1.00 \\
\hline $9-11$ & $0.58(0.38$ to 0.90$)$ & $0.67(0.43$ to 0.91$)$ & $0.95(0.60$ to 1.51$)$ \\
\hline $12-14$ & $0.57(0.39$ to 0.83$)$ & $0.72(0.48$ to 1.05$)$ & 1.45 (0.95 to 2.22$)$ \\
\hline $15+$ & $0.59(0.29$ to 1.20$)$ & $0.75(0.36$ to 1.65$)$ & 1.97 (0.93 to 4.17$)$ \\
\hline \multicolumn{4}{|l|}{ Household smoking characteristics } \\
\hline Number of smokers & - & 1.00 & 1.00 \\
\hline One & & $1.68(1.21$ to 2.35$)$ & 1.59 (1.13 to 2.23$)$ \\
\hline Two & & $2.60(1.67$ to 4.06$)$ & $2.29(1.44$ to 3.64$)$ \\
\hline Three or more & & 7.96 (3.70 to 17.11$)$ & 7.22 (3.16 to 16.46$)$ \\
\hline Household smoking rule & - & & \\
\hline Not allowed & & 1.00 & 1.00 \\
\hline Generally not allowed & & $1.21(0.76$ to 1.94$)$ & $1.32(0.82$ to 2.15$)$ \\
\hline Allowed & & 1.53 (1.10 to 2.13$)$ & 1.49 (1.06 to 2.09$)$ \\
\hline \multicolumn{4}{|l|}{ Adolescents' characteristics } \\
\hline \multicolumn{4}{|l|}{ Sex } \\
\hline Male & 1.00 & 1.00 & 1.00 \\
\hline Female & $0.45(0.34$ to 0.61$)$ & $0.43(0.33$ to 0.59$)$ & $0.45(0.32$ to 0.62$)$ \\
\hline \multicolumn{4}{|l|}{ Age (years) } \\
\hline $15-16$ & 1.00 & 1.00 & 1.00 \\
\hline $17-19$ & 3.89 (2.71 to 5.58$)$ & 3.95 (2.74 to 5.69$)$ & 2.38 (1.62 to 3.49$)$ \\
\hline Social status & - & - & \\
\hline Full student & & & 1.00 \\
\hline Only working or working and studying & & & $2.81(1.86$ to 4.25$)$ \\
\hline Neither studying/neither working & & & 4.56 (2.85 to 7.30$)$ \\
\hline School delay (years) & - & - & \\
\hline None & & & 1.00 \\
\hline One & & & 2.34 (1.37 to 3.96$)$ \\
\hline Two & & & 2.81 (1.69 to 4.69$)$ \\
\hline Four or more & & & 4.27 (2.87 to 6.35$)$ \\
\hline
\end{tabular}

added the youth level of education and social status factors, retaining only the proximal factors that were statistically significant (model 3). The analysis was controlled for potential confounders-in this case, the variables maintained from the previous stages. The proximal variables were adjusted for the distal and intermediate variables (table 3 ).

\section{RESULTS}

Among the participants, 6.2\% were current smokers (95\% CI 5.4 to 7.1 ), and $5.4 \%$ (95\% CI 4.6 to 6.3) reported being daily smokers, with a statistically significant difference between male and female participants (male $7.2 \%$; $95 \%$ CI 5.9 to 8.6 ; female $3.6 \%$; $95 \%$ CI 2.7 to $4.6 ; \mathrm{p}<0.001)$. All of the current smokers had smoked at least 100 cigarettes in their lifetimes. Among daily smokers, the mean (and median) numbers of cigarettes smoked per day were $11.8(10.0)$, which were approximately the same in male (12.3 and (10.0)) and female participants (10.8 and (10.0)).
The distributions of participants according to socioeconomic and household characteristics are presented in table 1 . Almost $60 \%$ of the adolescents were between 17 and 19 years of age, a great majority lived in urban dwellings, $50 \%$ were men, and $54 \%$ (95\% CI 52.3 to 55.7) matched the level of schooling expected for their ages (table 1). Most of the participants were full-time students at the time of the interview. In total, almost $60 \%$ of adolescents lived in households concentrated between the first (lowest) and third quintiles of income distribution, and the majority lived in houses headed by men with up to 8 years of schooling and in households with smoking restrictions.

In the univariable analysis (table 2), male sex, older age and black skin colour were all significantly associated with a greater likelihood of being a regular smoker. The following factors in the household context were significantly associated with an increased chance of an adolescent being a current smoker: being in the fourth quintile of per capita income distribution and the head of the household having a lower level of education. 
The OR of smoking increased with the number of smokers in the same household, and it was greater in homes in which smoking was allowed. The chance of smoking rose as the number of delayed years of education increased, and it was greater among adolescents who were studying and working, only working or neither studying nor working, compared to full-time students at the time of data collection.

In the hierarchical analysis (table 3), exposure to tobacco smoking remained significantly lower among female participants, although it increased with age. In the household context, the association between smoking and the educational level of the head of the household was no longer significant $(\mathrm{p}=0.847,0.082$ and 0.077 for 9-11, 12-14 and 15 or more years of schooling, respectively). In addition, in the household context, the OR, regarding the number of smokers in the household, for being exposed to three or more smokers was as high as 7.22 (95\% CI 3.16 to 16.46 ), demonstrating a significant upward trend $(\mathrm{p}<0.001)$. Exposure to tobacco smoking remained significantly higher among adolescents living in households without smoking restrictions. After considering the effects of household socioeconomic and smoking factors, the chances of smoking remained significantly associated with the number of years of delaying of school, showing a significant upward trend $(p<0.001)$. The chances of smoking were about three times greater among individuals who were only working or who were working and studying, and five times higher among those who were neither studying nor working when compared with adolescents who were full-time students.

\section{DISCUSSION}

Our results confirm that school delay, as well as not attending school, and early entrance into the work force are associated with a greater likelihood of tobacco smoking among teenagers. In general, our results support the hypothesis that socioeconomic inequality in smoking is established at younger ages. In addition, our results confirm the importance of household smoking exposure in teenage smoking, reinforcing the evidence that smoking behaviour can be contagious. ${ }^{21} 22$ The findings are particularly relevant as socioeconomic disparities in smoking behaviour among youth are predictive of future disparities in smoking, as well as in morbidity and mortality from chronic diseases. ${ }^{23}$

We found important and strong associations between school engagement and smoking. The chances of smoking were substantially greater among adolescents who were no longer attending school, regardless of what they were or whether or not they were working. Moreover, we also found that the chances of smoking increased as the number of years of school delay increased. School delay and leaving school are important markers of current as well as future lower socioeconomic status, independent of youth health, parental education and sex. ${ }^{24}$ Recently published analysis of US survey data showed that at the population level, education gaps among adult smokers are produced mostly by educational inequalities in initiation rather than in quitting smoking. ${ }^{25}$

Likely explanations for the association between school delay and school abandonment and smoking include less information on the health consequences of smoking and differences in access to and effectiveness of cessation treatments. Lower reading skills were associated with becoming a regular smoker, as well as the current amount smoked, in a cohort analysis. ${ }^{26}$ Several studies have indicated that failure to complete high school is associated with substance use, including the use of tobacco. $^{27}$

Educational underachievement and dropping out of school remain serious problems in Brazilian society: only $50 \%$ of adolescents who enter high school will graduate. In $2009,15 \%$ of adolescents with $15-17$ years of age were not in high school. Among those who were enrolled, one-third were not in the correct school grade for their ages. ${ }^{28}$ Researchers in the area have cited disillusion, poverty, early parenthood and criminal involvement as the main reasons regarding this finding. ${ }^{28}$

The household environment is the most important source of cultural and social values for children and adolescents, and it is the most proximal context for them. Adolescents from non-smoking homes are less likely to start or develop smoking habits. ${ }^{29}$ Our results showed a very sharp, positive relationship between the number of smokers in the household and the likelihood that a youth would smoke. There is compelling evidence that the children of smoking parents are more likely to initiate smoking in adolescence than the children of nonsmoking parents, thus transmitting the single greatest cause of preventable death from generation to generation. $^{29}$ Beyond promoting smoking, exposure to other smokers at home also seemed to hamper quitting attempts and smoking cessation among adolescent Chinese smokers. ${ }^{30}$

Additionally, our results corroborate the growing and consistent evidence that home smoking restrictions protect non-smokers from second-hand smoke as it reduces smoking exposure at the household level. These results also suggest that home smoking restrictions contribute to reduce youth smoking behaviour. Moreover, a completely smoke-free home appears to send a stronger anti-smoking message than partial restrictions, and a smoke-free home might be more influential in earlier, rather than later, stages of the smoking continuum. ${ }^{29-33}$ Late adolescence is a period characterised by an increasing role instability and major life options, such as whether to start working, go to college, leave home and so on. As adolescents approach the adulthood, the unhealthy behaviours initiated earlier might be abandoned or could develop into more consolidated attitudes. Thus, it is a crucial period to approach the promotion of health. Our results support the evidence 
that socioeconomic inequalities in smoking begin in adolescence and are likely to endure and even increase because smoking is linked to school delay and abandonment, which reduce the likelihood of having a better job and better life conditions in the future.

\section{COMIMENTS AND LIMITATIONS}

Unfortunately, our work lacked information about parent and adolescent peer behaviours, which are known to be important risk factors for smoking. In addition, we had no data on the relationship between the respondents and other smokers in the household. For this reason, we cannot estimate whether smoking parents, compared with other smokers, had a different impact on adolescent smoking. Despite being a cross-sectional study, it is quite unlikely that youth smoking produces disadvantages at the household level. However, it is possible that youth smoking is involved in youth school performance in a vicious cycle: the same problems that result in school delay (or abandonment) also influence smoking, and these two behaviours reinforce each other. We believe that low socioeconomic status, with all that it implies (in terms of culture and access to information), is the primary factor behind these behaviours.

The major associations observed in this study indicate that keeping teenagers at school could help to prevent smoking and to reduce the health inequalities associated with this habit. It is undeniable that all adolescents must be in school. However, because smoking seems to be a transmissible behaviour, reducing the delays in education and school abandonment must be accompanied by reductions in smoking exposure in the home. This information is important as it identifies the groups where the current tobacco control measures do not have a desired effect.

Contributors SMB coordinated the design, analysis and writing the manuscript. LG participated in the design, analysis and in preparing the manuscript. RCdF participated in the design and preparation of the manuscript. SMB and LG performed the statistical analyses. All of the authors wrote the article, and they were responsible for the final content of the manuscript. All of the authors contributed to the design of the research and read, edited and approved of the final draft of the manuscript.

Funding Brazilian National Heath Foundation (FNS, research grant number 23072.038965/2012-79). SMB is a research fellow of the National Research Council (CNPq, grant number 300159/99-4). RCF received a research grant from CNPq (grant number 380758/2013-0).

Competing interests None.

Ethics approval This study was conducted with the approval of the Brazilian National Ethics Committee.

Provenance and peer review Not commissioned; externally peer reviewed.

Data sharing statement No additional data are available.

Open Access This is an Open Access article distributed in accordance with the Creative Commons Attribution Non Commercial (CC BY-NC 3.0) license, which permits others to distribute, remix, adapt, build upon this work noncommercially, and license their derivative works on different terms, provided the original work is properly cited and the use is non-commercial. See: http:// creativecommons.org/licenses/by-nc/3.0/

\section{REFERENCES}

1. WHO. http://www.who.int/tobacco/surveillance/en_tfi_gats_2010 brazil.pdf (accessed 20 May 2013).

2. Levy D, de Almeida LM, Szklo A. The Brazil SimSmoke policy simulation model: the effect of strong tobacco control policies on smoking prevalence and smoking-attributable deaths in a middle income nation. PLoS Med 2012;9:e1001336.

3. Szklo AS, de Almeida LM, Figueiredo VC, et al. A snapshot of the striking decrease in cigarette smoking prevalence in Brazil between 1989 and 2008. Prev Med 2012;54:162-7.

4. Hosseinpoor AR, Parker LA, d'Espaignet E, et al. Socioeconomic inequality in smoking in low-income and middle-income countries: results from the World Health Survey. PLOS ONE 2012;7:e42843.

5. Instituto Nacional de Câncer (Brasil). Global adult tobacco survey Brazil 2008 / Instituto Nacional de Câncer.-Rio de Janeiro: INCA, 2010, 208 p. http://www.who.int/tobacco/surveillance/en tfi gats 2010_brazil.pdf

6. Federico $B$, Costa $G$, Kunst $A E$. Educational inequalities in initiation, cessation, and prevalence of smoking among 3 Italian birth cohorts. Am J Public Health 2007;97:838-45.

7. Giovino GA, Mirza SA, Samet JM, et al. Tobacco use in 3 billion individuals from 16 countries: an analysis of nationally representative cross-sectional household surveys. Lancet 2012;380:668-79.

8. Palipudi KM, Gupta PC, Sinha DN, et al. Social determinants of health and tobacco use in thirteen low and middle income countries: evidence from Global Adult Tobacco Survey. PLOS ONE 2012;7: e33466.

9. Moolchan ET, Ernst M, Henningfield JE. A review of tobacco smoking in adolescents: treatment implications. J Am Acad Child Adolesc Psychiatry 2000;39:682-93.

10. Park S, Lee JY, Song TM, et al. Age-associated changes in nicotine dependence. Publ Health 2012;126:482-9.

11. Greenwood PA, Engels RC, Olsson CA, et al. Patterns of adolescent smoking and later nicotine dependence in young adults: a 10-year prospective study. Public Health 2010;124:65-70.

12. O'Loughlin J, DiFranza J, Tyndale RF, et al. Nicotine-dependence symptoms are associated with smoking frequency in adolescents. Am J Prev Med 2003;25:219-25.

13. Riggs NR, Chou CP, Li CY, et al. Adolescent to emerging adulthood smoking trajectories: when do smoking trajectories diverge, and do they predict early adulthood nicotine dependence? Nicotine Tob Res 2007;9:1147-54.

14. Household survey on behaviour risk factors and self-reported non-communicable diseases. Rio de Janeiro: National Cancer Institute, Health Surveillance Division, Ministry of Health, 2004

15. Goldade $\mathrm{K}$, Choi $\mathrm{K}$, Bernat $\mathrm{DH}$, et al. Multilevel predictors of smoking initiation among adolescents: findings from the Minnesota Adolescent Community Cohort (MACC) study. Prev Med 2012:54:242-6.

16. Tjora T, Hetland J, Aarø LE, et al. Distal and proximal family predictors of adolescents' smoking initiation and development: a longitudinal latent curve model analysis. BMC Public Health 2011;11:911.

17. Hallal PC, Clark VL, Assunção MC, et al. Socioeconomic trajectories from birth to adolescence and risk factors for noncommunicable disease: prospective analyses. J Adolesc Health 2012;51(6 Suppl): S32-7.

18. Barreto SM, Giatti L, Casado L, et al. Contextual factors associated with smoking among Brazilian adolescents. J Epidemiol Community Health 2012;66:723-9.

19. Sanchez ZM, Opaleye ES, Martins SS, et al. Adolescent gender differences in the determinants of tobacco smoking: a cross sectional survey among high school students in São Paulo. BMC Public Health 2010;10:748.

20. Victora CG, Huttly SR, Fuchs SC, et al. The role of conceptual frameworks in epidemiological analysis: a hierarchical approach. Int J Epidemiol 1997;26:224-7.

21. Schuck K, Otten R, Engels RC, et al. Birectional influences between parents and children in smoking behavior: a longitudinal full-family model. Nicotine Tob Res 2013:15:44-51.

22. Christakis NA, Fowler JH. Social contagion theory: examining dynamic social networks and human behavior. Stat Med 2013;32:556-77.

23. Wardle J, Jarvis MJ, Steggles N, et al. Socioeconomic disparities in cancer-risk behaviors in adolescence: baseline results from the Health and Behaviour in Teenagers Study (HABITS). Prev Med 2003;36:721-30.

24. De Ridder KA, Pape K, Johnsen R, et al. School dropout: a major public health challenge: a 10-year prospective study on medical and non-medical social insurance benefits in young adulthood, the Young-HUNT 1 Study (Norway). J Epidemiol Community Health 2012;66:995-1000. 
25. Maralani V. Educational inequalities in smoking: the role of initiation versus quitting. Soc Sci Med 2013;84:129-37.

26. Martin LT, Haas A, Schonlau M, et al. Which literacy skills are associated with smoking? J Epidemiol Community Health 2012;66:189-92

27. Henry KL, Knight KE, Thornberry TP. School disengagement as a predictor of dropout, delinquency, and problem substance use during adolescence and early adulthood. $J$ Youth Adolesc 2012;41:156-66.

28. IPEA. http://www.ipea.gov.br/portal/index.php?option=com content\&view $=$ article\& $\mathrm{id}=15818 \&$ catid $=159 \&$ ltemid $=75$ (accessed 15 Feb 2013).
29. Gilman SE, Rende R, Boergers J, et al. Parental smoking and adolescent smoking initiation: an intergenerational perspective on tobacco control. Pediatrics 2009;123:e274-8.

30. Wang MP, Ho SY, Lo WS, et al. Smoking family, second-hand smoke exposure at home, and quitting in adolescent smokers. Nicotine Tob Res 2013;15:185-91.

31. Emory K, Saquib N, Gilpin EA, et al. The association between home smoking restrictions and youth smoking behaviour: a review. Tob Control 2010;19:495-506.

32. Fichtenberg CM, Glantz SA. Effect of smoke-free workplaces on smoking behaviour: systematic review. BMJ 2002;325:188.

33. Mills AL, Messer K, Gilpin E, et al. The effect of smoke-free homes on adult smoking behavior: a review. Nicotine Tob Res 2009;11:1131-41. 